University of Warwick institutional repository: http://go.warwick.ac.uk/wrap

This paper is made available online in accordance with publisher policies. Please scroll down to view the document itself. Please refer to the repository record for this item and our policy information available from the repository home page for further information.

To see the final version of this paper please visit the publisher's website. Access to the published version may require a subscription.

Author(s): Steve Fuller

Article Title: Thinking the Unthinkable as a Radical Scientific

Project

Year of publication: 2010

Link to published article:

http://dx.doi.org/10.1080/08913811.2010.541691

Publisher statement: This is an electronic version of an article published in Fuller, S. (2010). Thinking the Unthinkable as a Radical Scientific Project, 22(4). pp. 397-413. Critical Review (Philadelphia): a journal of politics and society is available online at:

www.tandfonline.com 


\section{THINKING THE UNTHINKABLE AS A RADICAL SCIENTIFIC PROJECT Steve Fuller}

One of Philip Tetlock's more bracing studies of counterfactual reasoning in political judgement concerns what he calls 'thinking the unthinkable' (Tetlock 2003), recalling the title of Herman Kahn's notorious 1962 book about our prospects of surviving a limited nuclear war, which Kahn regarded as reasonably good. In what follows, I shall explore the significance of using the strategy implied here for the study of expertise namely, experts and lay people are persuaded to consider possibilities whose realization they would normally oppose, perhaps even in principle. Before turning to my own examples, I shall focus on Tetlock (2005), which is mostly a scientific study of political judgement. However, the import of the study, which systematically undermines the time-honoured distinction between 'political judgement' and 'political science', is generalisable across many fields that claim to uphold a sharp divide between the experienced practitioner and the theoretically informed scientist. In Tetlock's hands, the scientist appears to come out the stronger party, although, so I shall argue, at the cost of assuming some responsibility for the fate of the practices he has experimentally disrupted. I should say at the outset that for me this point is more of a challenge than a criticism of Tetlock's work, which I strongly support.

To be sure, the distinction between political judgement and political science has been drawn at different times, on different grounds and to different effect. For example, Plato's 'political science' might be read as aiming to transcend the volatility of opinion in which Aristotle's conception of 'political judgement' naturally swims and arguably renders a virtue, given the value he placed on rhetoric. However, as an academic discipline called 'political science' emerged in the $20^{\text {th }}$ century that selfconsciously modelled itself on the methods of the natural sciences, 'political judgement' became increasingly consigned to that amalgam of tradition-cum-personal experience that has been often mystified as 'tacit knowledge' (Polanyi 1957).

Moreover, 'political judgement' in this sense was supposedly not limited to practicing politicians but also possessed by political commentators, or 'pundits', whose stock in trade is to predict phenomena ranging from emerging trends to election outcomes. While Tetlock's official target is punditry, his systematically analytic approach to politics in aid of a nomothetic perspective casts substantial doubt on whether even politicians know more about policy-making than political scientists. Indeed, Tetlock presumes that 'political judgement' in some normatively desirable sense is ultimately a species of applied political science, in that politicians and political scientists are engaged in the same sorts of cognitive processes (including biases), albeit subject to rather different time and resource constraints.

Let us start by stepping back and asking a basic question: Why is prediction an epistemically significant activity at all? No one doubts that it is fun, and sometimes lucrative, to forecast the winners of games and elections and to place bets at a casino or invest in the stock market. But beyond the entertainment value - the long-term psychological effects of which should not underestimated - predictions serve three epistemic functions.

First, they force us to simulate a state of the actual world, typically one located in the future. This goes against the grain of how we normally register things, namely, as a space of possibilities that are realized to varying degrees as we move through space 
and time, responding to external cues; hence, the fluidity of our memory and imagination (For a psychology that has taken this point as foundational for the discipline, see Hammond and Stewart 2001). For the predictor, this fluidity becomes the source of fallibility.

Second, predictions are not only about the actual world but also in it. They are public events that cannot accommodate the full range of world-views that people normally carry around in the heads, which are easily adjusted in the face of events in which they have no personal investment. But predictions demand just such investments and hence, in the face of failure, potentially exact unwelcomed costs.

Third, precisely because predictions are public events experienced by predictors and their audiences, preparations of various sorts can be made in the time leading up to a prediction's outcome. Although professional predictors are loath to admit it, predictions may even be said to license, if not authorise these activities. Together they trigger a society's cognitive immune system, so to speak. Here we enter the realm of self-fulfilling and self-defeating prophecies - but equally the space for radically revising one's world-view while still appearing rational, the mark of a theory's falsifiability that Karl Popper deemed to be the cornerstone of the scientific method.

Now, let us develop an implicit distinction in Tetlock's discussion of failed predictions: 'almost right (but wrong)' versus 'almost wrong (but right)'. Tetlock tends to treat claims to the former as self-justifying defensive responses to predictive failure. At the same time, he seems to regard the latter as the presumptive epistemic state of most predictive successes. In other words, Tetlock holds all political predictors guilty of systemic error, until proven otherwise. It is easy to appreciate his suspicion mainly because by playing on the ambiguous epistemic space between 'almost right' and 'almost wrong', it is easy to leave the impression that one is exactly right. I tested this hypothesis against one of the best publicised 'successful' social scientific predictions of recent times, namely, the collapse of the Soviet Union, made in 1978 by the distinguished US sociologist, Randall Collins (1995). On closer inspection, the prediction turns out to be both 'almost right' and 'almost wrong' but in any case, not exactly right. While Collins' general theoretical model was vindicated in that he predicted that the tipping point would come from social movements mobilising around dissenting elites, it failed to assign a specific role to the media in expediting this mobilisation. Thus, a process that on the basis of past revolutions Collins had predicted would take 30-50 years ended up happening in a little more than a decade.

Chapter one of Tetlock (2005) provides a set of compelling reasons for not trusting correct predictions of any sort. After all, anyone who predicts regularly is bound to hit a few targets - and if you predict the same target long enough, you are bound to hit that one. In these cases, one should be looking for the predictor's success/failure ratio. There is also the methodological problem of deciding exactly what had been predicted and whether it actually occurred. Unless one is predicting a specific outcome in an independently determined process, such as an election result, one may be faced with a hopelessly moving target, as predictors rationally reconstruct both their initial and final knowledge states. Finally, and perhaps most interestingly, Tetlock suggests that successful predictions may be based on normatively dubious forms of knowledge that involve insider information, torture and coercion, or quite simply models of the 
human condition based on deep-seated 'irrational' tendencies that we might be otherwise wish to minimise or eliminate in the future.

Tetlock's gold standard of political judgement combines the two leading philosophical theories of truth, correspondence and coherence - namely, one predicts the right thing and for the right reasons. On the one hand, the predictor must do better than being 'right but almost wrong', in that she must have a coherent causal account of why an event should have occurred, not just the simple claim that it would occur. On the other hand, the predictor must do better than being 'wrong but almost right', in that her conceptually sound model must also capture specific actual outcomes. This is the context for understanding Tetlock's appropriation of the contrast first popularised by Erasmus of the fox and the hedgehog, the former knowing many little things and the latter one big one. Foxy predictors are always on the verge of incoherence, whilst the hedgehogs fail on strict accuracy.

The value of crystallising political judgement as the ability to predict the right thing for the right reasons is that such a prediction forces you to confront the modal structure of your world-view, not least the amount of control that you ascribe to the agents populating it. Instead of parsing the difference between hedgehogs and foxes as the number of things that they "know," one might say that foxes operate with what I have called an 'underdetermined' world-view, one that allows for many reversals of fate, whereas hedgehogs adopt an 'overdetermined' world-view that posits a dominant tendency onto which all paths ultimately converge (Fuller 2008). Foxes see hidden necessary conditions where hedgehogs detect only temporary interference to the main narrative flow. Much of this boils down to historical standpoint: Foxes see the world in prospect, hedgehogs in retrospect. Those for whom politics consists of lurching from one election to the next tend to behave like foxes, whereas hedgehogs are more likely to see politics as long-term movements of social transformation. Much of the authority that hedgehogs command in the media - something that Tetlock bemoans may be attributed to their ability to speak as if their world-view is destined to triumph whilst they address questions of how exactly that is supposed to happen. They make up for their predictive inaccuracy by personifying the future they would see come about. As I shall explore below, this point suggests that hedgehog may not be quite the right species for these pundits.

It is not clear whether Tetlock is interested in improving political judgement for its own sake or to improve the conduct of public life. In any case, the two goals are distinct and each controversial in its own way, the latter perhaps more so. On the one hand, Tetlock might be making a case for the cultivation of intellectual virtue in the punditry, which would be in line with his implicit view that political judgement is an unrigorous version of applied political science. But on the other hand, would the conduct of public life itself be improved if pundits could be nudged to issue more accurate predictions, to own up to their failures, and to update their beliefs in ways that conform to the probability axioms and Bayes' theorem? The answer is not clear, mainly due to lack of evidence about the consequences of such changes.

Now consider a more modest policy to improve the conduct of public life that does not require any instruction of the punditry: a careful media record of pundits' success ratio. Even if, as Tetlock himself seems to believe, this policy would improve public life, would it be the result of people gravitating to the pundits with better track 
records? On the contrary, the exercise might give people the opportunity to infer the narrative thread that connects the various predictions made and then decide whether they would like to contribute to a more exact realization of the narrative so inferred. I purposely say 'inferred' rather than 'implied' in order to allow that people will project unintended meanings onto track records. For example, a string of 'near miss' predictions by a pundit who sends a clear message - one of Tetlock's hedgehogs might spur those resonant to the message to transform the political-economic order in ways that increase the likelihood that the pundit's predictions will hit their targets in the future. Even if the pundit herself recognised with hindsight the incompetence of these predictions, that need not stop others from interpreting them as evidence for a systematically suppressed reality that deserves full expression.

We normally think of self-fulfilling and self-defeating prophecies as resulting from the prior announcement of a prediction that triggers actions contributing to its fulfilment or defeat. But here we are considering the prospect of a self-avenging prophecy inspired by the attractiveness of the alternative reality inferred from a string of already falsified predictions. This point can be fully appreciated by adding to Tetlock's political menagerie. The fox has had many foils - not only Erasmus' hedgehog but also Machiavelli's lion: The lion rules by focused shows of force, as opposed to the fox's diverse displays of cunning. Whereas the fox cajoles and adapts, often with the net effect of dissipating its energies, the lion is inclined simply to eliminate opponents who stand in its way. In that respect, the lion extends the hedgehog's explanatory idée fixe into political strategy, as, say, when a Marxist academic crosses the line from possessing a hegemonic theory to being possessed by a hegemonic ideology.

Tetlock's failure to take the full measure of leonine politics can be seen in his conclusion that hedgehogs fare better in static environments and foxes in more dynamic ones (Tetlock 2005: 251). He presumes that both political animals simply adapt to the world -- albeit each in its own inimitable way -- rather than create new opportunities, let alone recover lost ones intimated in their failed predictions. This is probably an artefact of Tetlock's treatment of political judgements as, to recall the old speech act jargon, 'constatives' rather than 'performatives' (Austin 1962). In other words, his concern is exclusively with whether the judgements match up against their target referents rather than with whatever consequences might flow from the very fact that those judgements were issued. Thus, Tetlock may be guilty of misreading the mass media's preference for pundits who are hedgehogs rather than foxes. These hedgehogs may be lions in disguise - that is, pundits whose predictions are themselves meant to be interventions that reinforce or subvert existing political tendencies. Here the media may not be so much reporting politics as providing an alternative channel for its conduct. From this standpoint, Tetlock's own disruptive research constitutes a counter-move, one designed precisely to inhibit the hedgehog's more leonine tendencies by luring pundits from their epistemic comfort zones, thereby revealing the limits of their expertise. It is clear that of the two species of pundit, Tetlock prefers the fox, not least because its more self-consciously limited horizons give it less capacity for causing lasting damage.

Critics often accuse me of 'scepticism' about expertise because I see expertise primarily in sociological rather than epistemological terms (e.g. Fuller 1988: chap. 12; Fuller 2002: chap. 3; cf. Selinger 2003). In short, for me an expert is someone whose 
word is presumed by other people to decide matters of a certain kind. To be sure, the expert's decision may be underwritten by a coherent body of reliable and relevant knowledge. But such knowledge is neither necessary nor sufficient for expertise to be effective. What matters is that the expert's decision licenses a train of other judgements and actions that attempt to align the world with the decision. Sociologically speaking, expertise is the most potent non-violent form of power available. While there may be resistance to various expert pronouncements, the resistance is channelled in quite specific ways. Experts are clearly marked by their formal training, which opponents must somehow match before issuing a credible challenge, which itself must be conducted by epistemically approved means, typically by mobilising reasons and evidence in specially designated forums, such as peerreviewed journals and conferences.

However, it would be a mistake to conclude that 'rule by experts' entails a rigidly governed society. On the contrary, we currently live under such 'rule' and conditions are fluid. Given that the expert's power derives from her sphere of discretion, one should expect a variety of judgements and actions to be licensed. For example, two qualified physicians confronted with the same patient may offer quite different diagnoses and treatments. The mark of expert rule is that such variability is tolerated, instead of taken as grounds for charging incompetence on the part of the experts, if not incoherence of the body of expert knowledge itself. This helps to explain the socially destabilising effects of experts challenging each other. Under normal circumstances, experts are presumed competent in their spheres of discretion and are credited for the good consequences of their decisions but, as much as possible, are excused from the bad ones by attributing them to factors legitimately unforeseen by the expert. But this policy is predicated on experts exercising a measure of selfdiscipline in the kinds of cases they agree to decide. Put bluntly, they need to turn down cases whose initial likelihood of failure is too high.

This last point suggests that the appropriate ancient precedent for my view of expertise is not the sceptics but the stoics: Whereas the sceptics questioned our general ability to define concepts with sufficient certainty to serve as reliable bases for knowledge, the stoics proposed that our concepts work perfectly well in the paradigm cases for which they were intended but become uncertain beyond that point (Fuller 2005). The original example that distinguished these two positions remains enshrined in logic textbooks as 'the paradox of the heap', or 'sorites', to keep to the original Greek. It is basically the idea that one grain of sand does not constitute a heap, but if you keep adding more grains, at some point the next grain will constitute a heap. Thus, sceptics concluded that 'heap' - and, by extension, all concepts - is hopelessly unclear. For their part, stoics argued that all that is shown by the paradox is that concepts cannot be applied indefinitely.

Successful experts normally have a stoic's sense of the conceptual limits within which they should operate. Like Socrates, they know what they do not know. However, much of Tetlock's work is designed to nudge experts outside this epistemic comfort zone, effectively getting them to relax their self-discipline. While Tetlock sees himself as probing the limits of expert knowledge, he is arguably destroying expertise, or at least violating one of its essential preconditions by supposing that an expert in a given field should display a uniform competence in judging all matters logically and counterfactually related to that field - and not simply the range of matters on which 
the expert would normally be expected to pass judgement. Tetlock is most explicit on this point when he asks experts to unpack possible futures in terms of finer grained outcomes, only to discover (perhaps unsurprisingly) that they manage to confer on these specific possibilities greater plausibility than their original judgements of the more generally stated outcomes would logically permit (Tetlock 2005: 189-218).

An experiment of this sort reflects Tetlock's implicit understanding of judgment as applied science, that is, the translation of knowledge of potentially universal scope to specific cases. Thus, as Tetlock admits, the hedgehogs are better prepared than the foxes to parry what he calls "close-call" counterfactual scenarios, in which small perturbations in real conditions would have led to quite different outcomes. Hedgehogs tend to stick to their original predictive frameworks and explain away counterfactuals as "exceptions that prove the rule" or as products of overactive imaginations or unlikely factors, whereas the foxes are more easily led to admit many more realistic possible outcomes than their theories would seem to allow (Tetlock 2000: 212-13). Thus, playing the hedgehog, an international-relations "realist" (balance-of-power theorist) said, "I'll change my mind in response to real but not imaginary evidence. Show me an actual case of balancing failing" (ibid. 212). The difference seems to be that hedgehogs are firmly anchored in the paradigm cases of their expertise, whereas foxes are always playing with the limiting cases, making them better able to capture the nuances in real-world situations but also more easily disoriented when the divide separating the actual and possible worlds is blurred or erased, as when asked by the experimenter to consider close-call counterfactuals. At that point, one might say, the foxes treat the extra imagination required to specify possible outcomes as if it constituted additional evidence for their likelihood.

Tetlock's (2003) research into 'thinking the unthinkable' provides an entry point to further interpretation. When experts are asked to make fine-grained judgements about alternate pasts or futures, they are often forced to entertain, in his jargon, 'taboo cognitions', which is to say, that they must trade off a sacred value against a secular value. In the case of experts, the 'sacred value' violated in Tetlock's (2005) scenarios amounts to the boundary surrounding an expert's sphere of discretion. Of course, an expert can be made to overstep that boundary but then the nature of the judgement is transformed, rendering the expert, in some sense, humiliated. In that case, some follow-up action - what Tetlock calls 'moral cleansing' -- is needed to re-establish the expert's authority, evidence for which can be found among both foxes and especially hedgehogs, who are inclined to accuse the experimenter of impertinence, if not outright deception, in getting them to relax their normal standards of what is impossible or inevitable. The original home for such discussion of moral cleansing is Emile Durkheim's (1964) account of sacred and profane uses of space in society. Not surprisingly, in Tetlock's (2003) earlier thought experiments, devout Christians were asked to place monetary values on the termination of certain human lives or to entertain the psychodynamic consequences for Jesus had he been raised in a singleparent home.

It is important to be clear about exactly how Tetlock's thought experiments elicit 'taboo cognitions' from subjects. It is by inviting them to convert a difference in kind to one of degree, or to reduce a qualitative distinction to a quantitative one. When expert historians or pundits are cajoled into exploring possibilities other than those 
they normally consider permissible, the distinctness of their subject matter starts to disappear - one consequence of which, of course, is that other people start to appear equally expert. For example, once theologians take seriously the idea of pricing human lives, economists are implicitly brought into the conversation. Devote too much concern to Jesus' upbringing and psychoanalysts enter the picture, as in fact they did, courtesy of Albert Schweitzer.

A similar result awaits an ordinary religious believer who ascribes too many human qualities - even their greatest possible versions -- to the deity. This is why theological orthodoxy in the Abrahamic faiths has tended to treat God-talk analogically, not literally. Without this semantic boundary work, the Biblical claim that humans are created 'in the image and likeness of God' could easily slide into the ceding of theological ground to social scientists, as God comes to be seen as a utopian projection, a superlative human being whose powers we might come to approximate through collective effort. Thus, the 'profane' character of doctrines of human perfectibility and social progress has less to do with their formal opposition to organized religion than their direct competition with it, as in the salvation narratives promoted by Comtean positivism and Marxist socialism (Milbank 1990).

In general, we might say that rationality becomes a fully secular mental process once we become adept at making value tradeoffs. Decisions that had been previously regarded, in Tetlock's jargon, as 'taboo' (sacred v. profane) or 'tragic' (sacred v. sacred) become simply 'efficient'. Put a bit a more crassly: No end is unconditional everything has its price. Historically this view has been associated with a heightened sense of personal responsibility for the consequences of one's decisions. In other words, reason no longer possesses us - in the sense of compelling a particular outcome to our thinking: rather, we possess it. An interesting precedent for considering this matter is the social history of the sublimation of violence, which has evolved from our being driven to violence by animal instinct to more calculated inflictions of cruelty in service of some higher goal (cf. Collins 1974).

Explanations - as well as excuses and condemnations - for violent episodes in human history come most easily when they are presented as stand alone 'events' with clear perpetrators and victims, as in the case of the 'Holocaust'. Yet, much of this clarity is an artefact of hindsight created by retrospective accounts that privilege the perspective of one or the other side of the violence. Violence is sublimated when correctives to this historical bias are incorporated into one's own sphere of action. For example, in Nazi Germany, genocide was incrementally instituted over time, not as an explicit policy but as a by-product of some other policy that had the same consequences. The overall violence committed was diffused by making full use of two features of complex modern societies: the bureaucratisation of public administration (whereby each functionary's responsibility is formally circumscribed, placing each functionary's discretionary authority in the same position as that of an expert) and language's capacity to refer to something by its defining properties rather than its proper name. Of course, it also helps to be on the winning side of history, which the Nazis failed to be (Fuller 2006: chap. 14).

My interest here is, of course, not to rehabilitate the Nazis but to suggest a context in which Tetlock-like exercises in taboo cognition could serve to erode conventional moral intuitions in aid of fostering more advanced moral reflection. A comparable 
long-standing case for consideration is the range of politically permissible responses to extreme global poverty, which may succeed in achieving, in a more diffused and finessed way, what the Nazis arguably aimed for, namely, a very studied form of negligence that manages to subordinate the suffering of potentially identifiable classes of victims to some promised greater good. Here one could manipulate several variables in getting subjects to consider at what point, say, a sweatshop becomes a labour camp, starvation becomes torture, and so forth. It is important to stress that the point of such an exercise would not be to induce moral scepticism but to destroy the illusion that 'the immoral' is a realm clearly signposted and hence easily avoided by the scrupulous. Rather, much in the spirit of existentialism's 'dirty hands' principle, potential for immorality is present in all judgements, which are ultimately 'arbitrary' in the strict sense of requiring discretion for which one is then personally responsible. The result of such awareness may be to increase our capacity for decisiveness, tolerance and forgiveness.

But even outside the unavoidable controversies surrounding moral judgements, the cultivation of taboo cognitions can have explosive effects. The clearest cases in point may be drawn from the history of science. Imagine a time travelling Tetlock who asks a $16^{\text {th }}$ century anatomist to think about how the liver might function under conditions that would quite clearly threaten the normal functioning of the human body. For the anatomist, this would be an invitation to countenance a taboo cognition, as he would need to offset the secular value of sheer intellectual curiosity against religiously inspired normative constraints on the practice of anatomy itself, which limited dissections of the human body and, in any case, treated the liver as a proper part of the body, an organ, not a stand-alone piece of organic matter. Of course, the last five hundred years have served to secularise the study of the human body so that an anatomist today would find the question quite ordinary. 'Liver' is now defined in more functional than substantive terms - that is, not as something with a particular look, feel, composition or origin, but simply whatever can reliably act as the chemical conversion plant for the human body. In the meanwhile, the human body itself has come to be seen mainly as a self-maintaining system consisting of potentially replaceable parts that are increasingly made to order, and may routinely come to be so, if stem cell research continues to make progress.

I raise this point because the history of anatomy is indicative of what happened to most ancient forms of expertise in the wake of the $17^{\text {th }}$ century Scientific Revolution: Their objects lost their sacred boundaries as differences in kind were rendered into ones of degree, such that two states that had been seen as radically different (even violently opposed) - such as movement and rest, living and dead, earthly and stellar, human and animal - came to be seen as two poles of a continuum that may be studied by common means and even experimentally manipulated (Funkenstein 1986). The critical side of the Scientific Revolution conjured up thought experiments very much in the spirit of Tetlock's 'thinking the unthinkable', namely, to elicit contradictory responses at the conceptual edges of existing expertises that served to trigger a fundamental rethinking of - say, in Galileo's case -- the nature of motion (Kuhn 1977). The net effect of this transformation - the rendering of the constant variable, if you will - was a shift from Aristotle's view of reality as a patchwork of discrete domains of being to Newton's unified vision under which all objects are products of the same set of laws, rendered intelligible by the same set of cognitive processes, 
albeit operating in different proportions under different conditions. (The locus classicus of this thesis is Cassirer 1953).

In an early work, very much in the spirit of the cognitive and social psychology of science popular in the day, I proposed the experimental discipline of axioaetiotics, whose name is a Greek-rooted neologism for studying the value-causes nexus in people's thought (Fuller 1993: 167-175; cf. Axtell 1993). The premise of this discipline is that even the legitimacy of our basic concepts of epistemic authority not least those relating to science itself -- presuppose a certain understanding of how they came to acquire that authority, the limits of which could be tested if not subverted by presenting historical counterfactuals. Indeed, Thomas Kuhn notoriously, but correctly, claimed that practicing scientists needed an 'Orwellian' (aka Whig) understanding of their own history, one that airbrushed all the complexities and alternative trajectories of the past in aid of streamlined account that justifies the current research frontier being just as it is (Kuhn 1970: 167; cf. Fuller 2000: Introduction). These implicit narratives of legitimation are delicately poised between a hedgehog's overdetermined and a fox's underdetermined view of intellectual history. This normative equilibrium may be easily disturbed, as Tetlock (2005) does in chapters 5-7, by appealing to interpretations of the past that, while not part of the legitimatory lore, nevertheless are taken seriously by professional historians. An example from the history of science follows.

The idea that science gets at some fundamental reality seems to require that the foundational theory of modern physics, Newtonian mechanics, could have - even would have - been developed by someone else, had Newton never come along. The underlying intuition is clear enough: There is sufficient objective validity to Newton's project that others pursuing similar leads with similar information (as was the case in $17^{\text {th }}$ century Europe) sooner or later would have, more or less, arrived at his conclusions. In this respect, Newton himself was an historical accident vis-à-vis the scientific ideas and findings associated with him, which could (or would) have been eventually made by others. This is very much in the mould of the hedgehog, and it invites talk of scientific progress being hastened or arrested, but all within a common narrative framework.

However, not everything about the history of science can be as contingent as Newton's specific existence. It is also presumed that only within a certain range of historical possibilities could some Newton-like form of physics have developed. If not in Europe, such a physics would have developed only in a culture (perhaps China) that had already made conceptual and technical moves comparable to the intellectual giants on whose shoulders Newton proverbially claimed to have stood. Moreover, the cultural import of such alternate achievements in those other places and times would have to be similar. For example, it would be quite jarring to learn that the Chinese arrived at the concepts and formulae of Newtonian mechanics - but in the context of designing a children's game or some other culturally trivial activity. Science is more than simply knowing the right equations and making the right predictions: It also requires that that its practices are accorded high epistemic standing in society.

Thus, to suggest, say, that East Africans possessed the concept of quantum uncertainty prior to Western contact without having passed through anything comparable to the Newtonian revolution (Van Sertima 1983) or, less radically but 
more plausibly, that the modern principle of inertia was introduced by $14^{\text {th }}$ century scholastics who failed to see the lethal blow it dealt to the Church's geocentric cosmology (Duhem 1954) is to challenge at once orthodox opinions about science and the nature of the thing called 'science'. In the two cases just cited, the normative destabilisation was deliberate and has been palpable. The former was originally proposed as part of an argument for the equalisation of African and European forms of knowledge, the latter as part of an argument for the continuity of physical science and natural theology - both 'taboo cognitions', in Tetlock's sense.

I have employed versions of the latter taboo strategy in defending intelligent design theory as an alternative to the Neo-Darwinian orthodoxy in biology (e.g. Fuller 2010). In particular, I have stressed that science would not have acquired, and perhaps cannot continue to sustain, its 'view from nowhere' sense of objectivity towards all of reality - and not merely to what is relevant to our species survival - without faith in the idea that we have been specially designed to make sense of it all. This self-understanding of humanity is peculiar to the Abrahamic religions. In contrast, had Western science been consistently oriented towards species survival, as Darwinists urge, we would not have taken such a keen interest in, nor conferred so much cultural value on, nor, for that matter, risk so much on behalf of, the pursuit of reality's physical limits.

Darwin's ablest defender, Thomas Henry Huxley (1893) put the point well, when he said that Newton the Christian had to precede Darwin the apostate -- not the other way round - to explain the zeal with which we have reshaped nature in our own image, a project that would seem like sheer hubris, if not insanity, had humans always seen themselves as simply one amongst many species. (Huxley was worried that as Darwinism became part of humanity's self-understanding in the $20^{\text {th }}$ century, scientific progress would come to a halt.)

One can imagine presenting Huxley's counterfactual to irreligious scientists today, asking them to imagine how Western science would have reached the comprehensive achievement of modern physics, had Darwin come to be accepted first. They would probably think it possible, but it would be interesting to see exactly how they would flesh out the details of an alternate history that does not depart too far from the main tendencies in the actual history. In particular, where would one find the motive to conceptualise all of reality under a finite set of mathematical laws, if one begins with an essentially earthbound, species egalitarian view of the natural world? To be sure, a Darwin-first history would allow for the development of quite sophisticated technologies, including mathematical techniques, all in aid of human survival across vast swathes of space and time. Thus, the physical sciences could plausibly reach the heights of Chinese civilization. But the Chinese did not think it reasonable, or even interesting, to unify all of knowledge under a single intellectual rubric.

Of course, our scientist-subjects might dismiss all this scenario-mongering as sheer fantasy, as science really stands on its own track record, whatever theological motives may have been operative in the past. It is a pity, then, that our sense of science's track record is subject to so much confirmation bias. We easily recall and even oversell science's empirical and practical successes, while ignoring or underestimating the costs, failures and outright disasters. Perhaps the next frontier for 'thinking the unthinkable' is to get experts and lay people from a variety of backgrounds to draw up balance sheets for science. My guess is that the resulting track record will look so 
chequered that science may need to rekindle its ties to theology to ensure its future legitimacy.

\section{REFERENCES}

Austin, J.L. (1962). How to Do Things with Words. Cambridge MA: Harvard University Press.

Axtell, G. (1993). 'In the tracks of the historicist movement: Re-assessing the Carnap-Kuhn connection'. Studies in the History and Philosophy of Science 24: 119-146.

Cassirer, E. (1953). Substance and Function. (Orig. 1910). New York: Dover. Collins, R. (1974). 'Three Faces of Cruelty: Towards a Comparative Sociology of Violence. Theory, Culture and Society 1: 415-440.

Collins, R. (1995). 'Prediction in Macrosociology: The Case of the Soviet Collapse'. American Journal of Sociology 100 (6): 1552-1593.

Duhem, P. (1954). The Aim and Structure of Physical Theory (Orig. 1914) Princeton: Princeton University Press.

Durkheim, E. (1964). Elementary Forms of the Religious Life. (Orig. 1912) New York: Collier Macmillan.

Fuller, S. (1988). Social Epistemology. Bloomington IN: Indiana University Press. Fuller, S. (1993). Philosophy of Science and Its Discontents. $2^{\text {nd }}$ edn. (Orig. 1989). New York: Guilford Press.

Fuller, S. (2000). Thomas Kuhn: A Philosophical History for Our Times. Chicago: University of Chicago Press.

Fuller, S. (2002). Knowledge Management Foundations. Woburn MA: ButterworthHeinemann.

Fuller, S. (2005). 'Philosophy Taken Seriously but Without Self-Loathing'.

Philosophy and Rhetoric 38 (1): 72-81.

Fuller, S. (2006). The New Sociological Imagination. London: Sage.

Fuller, S. (2008). 'The Normative Turn: Counterfactuals and a Philosophical Historiography of Science'. Isis 99: 576-584.

Fuller, S. (2010). Science: The Art of Living. Montreal: McGill-Queens University Press.

Funkenstein, A. (1986). Theology and the Scientific Imagination. Princeton: Princeton University Press.

Hammond, K. and Stewart, T., eds. (2001). The Essential Brunswik. Oxford: Oxford University Press.

Huxley, T.H. (1893). 'Evolution and Ethics.' (Romanes Lecture)

http://aleph0.clarku.edu/huxley/CE9/E-E.html

Kuhn, T.S. (1970). The Structure of Scientific Revolutions. $2^{\text {nd }}$ edn. (Orig. 1962).

Chicago: University of Chicago Press.

Kuhn, T.S. (1977). 'A Function for Thought Experiments' (Orig. 1964). Reprinted in The Essential Tension (Chicago: University of Chicago Press), pp. 240-265.

Milbank, J. (1990). Theology and Social Theory. Oxford: Blackwell.

Polanyi, M. (1957). Personal Knowledge. London: Routledge and Kegan Paul.

Selinger, E. (2003). 'Expertise and Public Ignorance'. Critical Review. 15 (3) 375386.

Tetlock, P. (2003). 'Thinking the unthinkable: sacred values and taboo cognitions.' Trends in Cognitive Science 7(7): 320-324. 
Tetlock, P. (2005). Expert Political Judgement: How Good Is It? How Can We Know? Princeton: Princeton University Press.

Van Sertima, I., ed. (1983). Blacks in Science: Ancient and Modern. New Brunswick NJ: Transaction Publishers. 